\title{
Facial Image Perception and Appearance Management Behavior Based on Female University Students' Satisfaction with Their Faces
}

\author{
Seung-eun Choi \\ Department of Beautician Art, Ansan University, Ansan-si, Gyeonggi-do, Korea
}

Corresponding author: Seung-eun Choi, Department of Beautician Art, Ansan University, 155 Ansandaehak-ro, Sangnok-gu, Ansan-si, Gyeonggi-do 15328, Korea Tel.: +82 336515876

Email: makeyouup223@naver.com

Received December 30, 2016

Revised February 13, 2017

Accepted February 24, 2017

Published March 30, 2017

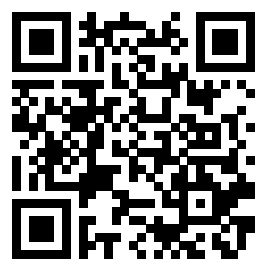

\begin{abstract}
Purpose: This study's purpose was to identify facial image perception and appearance management behavior based on female university students' satisfaction with their faces. Methods: With SPSS 23.0, 322 surveys were analyzed through frequency analysis, factor analysis, reliability analysis, correlation analysis, and t-test. Results: Analysis of facial image perception showed that importance was recognized in the order of balance-skin, features-hair, and face shape, and facial satisfaction was recognized in the order of features.hair, balance-skin, and face shape. Examination of facial image perception showed high facial importance, but relatively low facial satisfaction. Division of facial satisfaction into a low-satisfaction group and a high-satisfaction group showed a statistically significant difference. The low facial satisfaction group reflected higher importance of the face than the high facial satisfaction group. In appearance management behavior, the low facial satisfaction group showed greater belief that low facial satisfaction should be complemented through plastic surgery, makeup, and hair care than the high facial satisfaction group. However, there was no statistically significant difference in skin care and weight control. Conclusion: This study confirmed a difference in facial image perception and appearance management behavior based on female university students' satisfaction with their faces. Therefore, educating female university students to have appropriate perception about their appearance, including the face, is necessary.
\end{abstract}

Keywords: Facial image, Facial satisfaction, Facial importance, Appearance management behavior, Female university student

\section{Introduction}

얼굴은 인간의 신체에서 가장 대표적인 중심으로(Cunningham, 1986), 얼굴을 통하여 그 사람에 대한 정보, 연령, 직업, 생활수준 을 판단하고 이미지를 결정하게 된다(Hassin \& Trope, 2000). 따 라서 얼굴은 외모 중 인상형성에 가장 큰 영향을 미치며 가장 특징 적인 신체부위이다(Choi, 2009; Park \& Lee, 2009).

얼굴에 대한 정의는 해부학적 정의와 실용적 정의로 나뉘는데, 미용분야에서 정의하는 얼굴은 실용적 정의이다(Yoo, 2011). 얼굴 은 해부학적으로 눈, 눈썹, 코, 입, 입술, 턱 등을 말하며 두상과 머 리카락은 얼굴에 포함시키지 않는다. 그러나 미용분야에서는 두상
과 머리카락뿐만 아닌 이마와 목, 가슴, 어깨까지도 얼굴에 포함하 고 있다(Baek \& Kim, 2014).

얼굴 이미지는 얼굴 만족도와 얼굴 중요도로 구성되어 있으며 (Daibo, 2002; Guthrie et al., 2008), 이는 얼굴 각 부위별 형태와 크기, 피부, 얼굴의 각 구성요소인 눈, 코, 입술 등에 대한 스스로의 만족의 정도와 중요함의 정도를 의미한다(Kwon \& Park, 2013). 또 한 얼굴 이미지 중 선천적 요소는 얼굴형, 눈, 코, 입과 같은 신체적 으로 타고나는 것을 의미하고, 후천적 요소는 메이크업, 헤어스타 일, 의복 등과 같은 표현적 요소들을 의미하는데, 얼굴 이미지는 선 천적 요소만이 아닌 후천적 요소에 의해서도 결정되고 영향을 받는 다(Baek \& Kim, 2014). 이처럼 매우 중요하고 가장 대표되는 신체 
부위인 얼굴 이미지에 대한 인식은 외모를 가꾸고 관리하는 외모관 리행동과도 밀접한 연관이 있을 것으로 예상된다.

외모관리행동은 자기를 표현하기 위한 수단으로 실제 자신의 외 모와 이상적인 외모 차이를 줄이기 위하여 성형, 피부관리, 체중조 절, 메이크업, 헤어 등을 관리하는 행동을 통해 자신을 향상시키 고 변화시키는 행동을 의미한다(Kaiser, 1996). 외모는 어떠한 외 모관리행동을 하는가에 따라 변화시킬 수 있는 고정되지 않는 것이 다(Workman \& Johnson, 1991). 따라서 얼굴 이미지는 선천적 요 소와 함께 후천적 요소, 즉 메이크업이나 헤어스타일에 따라 인상 형성이 차이 나고, 결정된다(Lee et al., 2015; Oh \& Kim, 2006; Song et al., 2005; Yoon \& Yoo, 2001). 특히 얼굴은 체형과는 다 르게 본인의 관리 여부에 따라 만족도가 상승할 수 있기 때문에 (Hong, 2014), 신체에서 가장 중요한 얼굴에 대한 중요도와 만족도를 어떻게 인식하느냐에 따라 외모관리행동이 달라질 것으로 예상된다.

그러나 얼굴 이미지와 외모관리행동의 관계에 대한 연구는 매 우 제한적이다. 얼굴 이미지와 외모관리행동에 관한 선행연구로 는 라이프스타일 집단에 따른 얼굴만족 정도의 차이(Bae \& Ryoo, 2004), 얼굴형태 특성과 메이크업에 따른 얼굴 이미지(Song et al., 2005), 얼굴 만족도에 따른 화장 심리적 변인관계(Choi, 2009), 얼 굴 만족도와 퍼머넌트 메이크업 행동(Kwon \& Park, 2013), 얼굴 이미지 유형별 형성요소와 메이크업 디자인 효과(Baek \& Kim, 2014), 외모에 대한 사회문화적 태도가 얼굴 만족도 등에 미치는 영향(Lee et al., 2015) 등이 있다. 그러나 선행연구의 대부분이 얼 굴과 메이크업에 관련된 연구로 한정되어 있으며, 메이크업뿐만 아 닌 체중조절, 성형, 헤어 등을 포함한 전반적 외모관리행동과 얼굴 과의 관계에 대한 연구는 미비한 실정이다. 또한 얼굴이 신체 부위 중 가장 중요한 부위임에도 얼굴 만족도에 관한 연구가 대부분이 며, 얼굴의 만족도와 중요도를 포함한 얼굴 이미지를 어떻게 인식
하고 있는지, 얼굴 만족도와 중요도가 어떠한 관계가 있는지 파악 한 연구 또한 미비한 실정이다.

본 연구는 여대생을 연구대상으로 선정하였는데, 여대생은 청소 년에서 성인으로 가는 과도기로 외모에 관심이 가장 많아 신체외 모에 대한 흥미가 높으며(Ryan, 1966), 외모관리를 시작하는 시기 로 향후 뷰티 산업의 잠재적 고객이라 볼 수 있기 때문이다(Lee \& Gang, 2009). 이에 본 연구의 목적은 여대생을 대상으로 신체에서 가장 중요한 얼굴에 대한 얼굴 중요도와 얼굴 만족도의 얼굴 이미 지 인식을 살펴보고, 얼굴 만족여부에 따른 얼굴 이미지 인식과 전 반적인 외모관리행동 실태를 파악하고자 한다.

\section{Methods}

\section{1. 연구 문제}

본 연구의 연구문제는 다음과 같다. 첫째, 얼굴 이미지의 요인을 알아본다. 둘째, 외모관리행동의 요인을 알아본다. 셋째, 얼굴 이 미지 인식간의 상관관계를 알아본다. 넷째, 얼굴 만족여부에 따른 얼굴 이미지 인식과 외모관리행동을 알아본다.

\section{2. 연구 대상 및 자료 분석}

본 연구의 조사기간은 2016년 3월 5일부터 4월 15 일까지 서울 경기의 여대생을 대상으로 하였다. 총 350 부의 설문지를 배포하였 으며 불성실한 응답지 28 부를 제외한 322 부를 최종 분석에 이용하 였다. 자료 분석을 위해 SPSS for Windows 23.0 (IBM, USA)을 이 용하였고 빈도 분석, 신뢰도 분석, 요인 분석, 상관 분석, t-test 등 을 이용하였다.

\section{Table 1. Features of subjects}

\begin{tabular}{|c|c|c|c|}
\hline Variable & Item & Frequency $(\mathrm{N})$ & Percentage (\%) \\
\hline \multirow{6}{*}{ Most important part of appearance } & Face & 153 & 47.5 \\
\hline & Skin & 71 & 22.0 \\
\hline & Body & 70 & 21.7 \\
\hline & Hair & 4 & 1.2 \\
\hline & Fashion & 8 & 2.5 \\
\hline & Etc. & 16 & 5.0 \\
\hline \multirow{4}{*}{ Age } & $19-20$ & 74 & 23.0 \\
\hline & $21-22$ & 90 & 28.0 \\
\hline & $23-24$ & 125 & 38.8 \\
\hline & Over 25 & 33 & 10.2 \\
\hline \multirow{2}{*}{ School location } & Seoul & 141 & 43.8 \\
\hline & Gyeonggi & 181 & 56.2 \\
\hline Total & & 322 & 100.0 \\
\hline
\end{tabular}


1) 얼굴 이미지 인식

얼굴 이미지 인식은 얼굴 중요도와 얼굴 만족도를 Kwon \& Park (2013)의 선행연구를 본 연구에 맞게 수정 및 보완하여 얼굴형, 얼 굴크기, 이마, 턱선, 광대, 눈, 눈썹, 코, 입, 헤어, 전체조화, 피부 에 관한 문항으로 얼굴 중요도 12 문항, 얼굴 만족도 12 문항을 이용 하였다. 5점 리커트 척도를 사용하여 얼굴 중요도는 '매우 중요하다' 5점에서 '전혀 중요하지 않다' 1점, 얼굴 만족도는 '매우 만족한다' 5 점에서 '매우 불만족한다' 1점까지 표시하도록 하였다. 이후 얼굴 만 족여부를 얼굴 만족도의 전체평균 3.24 를 기준으로 평균 미만은 얼 굴 저만족 집단, 평균 이상은 얼굴 고만족 집단으로 분류하였다.

\section{2) 외모관리행동}

외모관리행동에 관한 선행연구 Hong \& Kim (2012), Kim et al. (2013)의 설문문항을 본 연구에 맞게 수정 및 보완하였다. 성형, 피
부관리, 체중조절, 메이크업, 헤어관리 등에 관하여 각각 5 문항씩 총 25 문항을 5 점 리커트 척도로 측정하여 점수가 높을수록 외모관 리행동의 정도가 높다고 평가하였다.

\section{Results and Discussion}

\section{1. 연구대상자의 특성}

본 연구의 연구대상자 특성을 알아보기 위해 빈도 분석을 실시한 결과는 Table 1과 같다. 전체 연구대상자 중 외모에서 가장 중요한 부 위는 얼굴(47.5\%)이라 응답하였으며, 피부(22.0\%), 몸매(21.7\%), 기타 (5.0\%), 의상(2.5\%), 헤어(1.2\%)의 순으로 나타났다. 연령은 만 23-24세 (38.8\%), 만 21-22세(28.0\%), 만 19-20세(23.0\%), 만 25세 이상(10.2\%) 의 순이었고, 학교 소재지는 서울이 $43.8 \%$, 경기가 $56.2 \%$ 로 나타났다.

Table 2. Factors of facial importance

\begin{tabular}{|c|c|c|c|c|c|c|}
\hline \multicolumn{2}{|c|}{ Factors } & Item & $\begin{array}{l}\text { Factor } \\
\text { loading }\end{array}$ & $\begin{array}{l}\text { Eigen } \\
\text { value }\end{array}$ & $\begin{array}{l}\text { Variance explained/ } \\
\text { Cumulative variance }\end{array}$ & $\begin{array}{c}\text { Reliability } \\
\text { (Cronbach's } \alpha)\end{array}$ \\
\hline \multirow{12}{*}{$\begin{array}{l}\text { Facial } \\
\text { importance }\end{array}$} & \multirow{5}{*}{ Face shape } & Face type & 0.63 & \multirow{5}{*}{3.49} & \multirow{5}{*}{ 29.15/29.15 } & \multirow{5}{*}{0.72} \\
\hline & & Face size & 0.71 & & & \\
\hline & & Forehead & 0.70 & & & \\
\hline & & Chin line & 0.68 & & & \\
\hline & & Cheekbone & 0.54 & & & \\
\hline & \multirow{5}{*}{ Features-Hair } & Eyes & 0.43 & \multirow{5}{*}{1.29} & \multirow{5}{*}{$10.75 / 39.91$} & \multirow{5}{*}{0.64} \\
\hline & & Eyebrows & 0.62 & & & \\
\hline & & Nose & 0.49 & & & \\
\hline & & Lips & 0.63 & & & \\
\hline & & Hair & 0.68 & & & \\
\hline & \multirow{2}{*}{ Balance-Skin } & Balance & 0.73 & \multirow{2}{*}{1.16} & \multirow{2}{*}{$9.66 / 49.57$} & \multirow{2}{*}{0.63} \\
\hline & & Skin & 0.78 & & & \\
\hline
\end{tabular}

Table 3. Factors of facial satisfaction

\begin{tabular}{|c|c|c|c|c|c|c|}
\hline \multicolumn{2}{|c|}{ Factors } & Item & $\begin{array}{l}\text { Factor } \\
\text { loading }\end{array}$ & $\begin{array}{l}\text { Eigen } \\
\text { value }\end{array}$ & $\begin{array}{l}\text { Variance explained/ } \\
\text { Cumulative variance }\end{array}$ & $\begin{array}{c}\text { Reliability } \\
\text { (Cronbach's } \alpha \text { ) }\end{array}$ \\
\hline \multirow{12}{*}{$\begin{array}{l}\text { Facial } \\
\text { satisfaction }\end{array}$} & \multirow{5}{*}{ Face shape } & Face type & 0.81 & \multirow{5}{*}{3.97} & \multirow{5}{*}{$33.13 / 33.13$} & \multirow{5}{*}{0.77} \\
\hline & & Face size & 0.72 & & & \\
\hline & & Forehead & 0.52 & & & \\
\hline & & Chin line & 0.72 & & & \\
\hline & & Cheekbone & 0.74 & & & \\
\hline & \multirow{5}{*}{ Features.Hair } & Eyes & 0.66 & \multirow{5}{*}{1.49} & \multirow{5}{*}{$12.45 / 45.58$} & \multirow{5}{*}{0.63} \\
\hline & & Eyebrows & 0.64 & & & \\
\hline & & Nose & 0.43 & & & \\
\hline & & Lips & 0.48 & & & \\
\hline & & Hair & 0.69 & & & \\
\hline & \multirow{2}{*}{ Balance-Skin } & Balance & 0.58 & \multirow{2}{*}{1.12} & \multirow{2}{*}{$10.45 / 56.03$} & \multirow{2}{*}{0.62} \\
\hline & & Skin & 0.59 & & & \\
\hline
\end{tabular}




\section{2. 얼굴 이미지와 외모관리행동의 요인}

본 연구의 얼굴 이미지(얼굴 중요도, 얼굴 만족도)와 외모관리행 동의 요인을 분석하였다. 각 문항들의 공통요인을 찾아 변수로 활 용하기 위해 주성분 분석 varimax를 이용하여 고유값이 1 이상인 것과 요인 부하량이 0.4 이상인 것을 선택하여 요인 분석을 실시한 결과, 각 3 개의 요인이 도출되었으며 신뢰도를 검증하기 위해 신뢰 도 분석을 실시하였다.

얼굴 이미지의 얼굴 중요도에서 신뢰도를 저하시키는 3 문항을 제거한 결과는 Table 2 와 같다. 그 결과 얼굴 중요도에서 얼굴형태 요인, 이목구비 · 헤어 요인, 전체조화 - 피부 요인의 총 3가지 요인 이 나타났다. 얼굴 중요도 요인1은 얼굴형, 얼굴크기, 이마, 턱선, 광대의 중요도로 구성되어 얼굴형태 요인이라 명명하였으며, 설명 력은 29.15 , 신뢰도는 0.72 로 나타났다. 얼굴 중요도 요인2는 눈, 눈썹, 코, 입의 이목구비와 헤어의 중요도에 관한 구성으로 이목구 비 · 헤어 요인이라 명명하였고, 설명력은 10.75 , 신뢰도는 0.64 로 나타났다. 얼굴 중요도 요인3은 얼굴의 전체적 조화와 피부에 대한 중요도로 구성되어 전체조화 - 피부 요인으로 명명하였고, 설명력 은 9.66, 신뢰도는 0.63 으로 나타났다.

얼굴 이미지의 얼굴 만족도에서 신뢰도를 저하시키는 3 문항을
제거한 결과는 Table 3과 같다. 얼굴 만족도 요인1은 얼굴형, 얼굴 크기, 이마, 턱선, 광대의 만족도로 구성되어 얼굴형태 요인이라 명 명하였으며, 설명력은 33.13 , 신뢰도는 0.77 로 나타났다. 얼굴 만 족도 요인2는 눈, 눈썹 코, 입, 헤어의 만족도로 구성되어 이목구 비 - 헤어 요인이라 명명하였고, 설명력은 12.45 , 신뢰도는 0.63 으 로 나타났다. 얼굴 만족도 요인3은 얼굴의 전체조화와 피부로 구성 되어 전체조화·피부 요인이라 명명하였으며, 설명력은 10.45 , 신 뢰도는 0.62 으로 나타났다.

외모관리행동에서 신뢰도를 저하시키는 4문항을 제거한 결과 총 5 가지 요인이 나타났으며 결과는 Table 4 와 같다. 외모관리행동 요 인1은 성형여부 및 의도, 안면윤곽수술 여부 및 의도, 반영구 시술, 지방흡입, 치열교정에 관한 문항으로 성형 요인이라 명명하였고, 설명력은 21.36, 신뢰도는 0.70 으로 나타났다. 외모관리행동 요인 2 는 화장품 사용, 피부관리 여부 등에 관한 문항으로 피부관리 요 인이라 명명하였으며, 설명력은 9.89, 신뢰도는 0.66 이며, 외모관 리행동 요인3은 운동, 식이요법 등으로 구성되어 체중조절 요인이 라 명명하였고, 설명력은 9.59, 신뢰도는 0.79 이다. 외모관리행동 요인4는 메이크업 행동, 메이크업 학습여부, 유행 메이크업 등으로 구성되어 메이크업 요인이라 명명하였으며, 설명력은 7.32 , 신뢰

Table 4. Factors of appearance management behavior

\begin{tabular}{|c|c|c|c|c|c|}
\hline Factors & Item & $\begin{array}{l}\text { Factor } \\
\text { loading }\end{array}$ & $\begin{array}{l}\text { Eigen } \\
\text { value }\end{array}$ & $\begin{array}{c}\text { Variance } \\
\text { explained/ } \\
\text { Cumulative } \\
\text { variance }\end{array}$ & $\begin{array}{c}\text { Reliability } \\
\text { (Cronbach's } \alpha)\end{array}$ \\
\hline \multirow{5}{*}{$\begin{array}{l}\text { Plastic } \\
\text { surgery }\end{array}$} & I had or intend to have plastic surgery. & 0.57 & \multirow{5}{*}{4.48} & \multirow{5}{*}{$21.36 / 21.36$} & \multirow{5}{*}{0.70} \\
\hline & I had or intend to have facial bone surgery. & 0.75 & & & \\
\hline & I had or intend to have semi-permanent makeup. & 0.60 & & & \\
\hline & I had or intend to have liposuction. & 0.67 & & & \\
\hline & I had or intend to have orthodontics for cosmetic purposes. & 0.65 & & & \\
\hline \multirow{4}{*}{ Skin care } & I know my skin type and use appropriate cosmetics. & 0.71 & \multirow{4}{*}{2.07} & \multirow{4}{*}{$9.89 / 31.26$} & \multirow{4}{*}{0.66} \\
\hline & I apply a pack or a massage more than once a week. & 0.67 & & & \\
\hline & I use functional cosmetics to prevent wrinkles and blemishes. & 0.64 & & & \\
\hline & I use sunscreen every day. & 0.63 & & & \\
\hline \multirow{3}{*}{$\begin{array}{l}\text { Weight } \\
\text { control }\end{array}$} & I do exercises for weight control. & 0.74 & \multirow{3}{*}{2.01} & \multirow{3}{*}{$9.59 / 40.85$} & \multirow{3}{*}{0.79} \\
\hline & I have been on a diet to lose weight. & 0.90 & & & \\
\hline & I have skipped meals for weight control. & 0.81 & & & \\
\hline \multirow{4}{*}{ Makeup } & I wear makeup every day. & 0.63 & \multirow{4}{*}{1.53} & \multirow{4}{*}{$7.32 / 48.18$} & \multirow{4}{*}{0.63} \\
\hline & I have learned how to use makeup from an academy or lessons. & 0.66 & & & \\
\hline & I have tried fashionable makeup. & 0.64 & & & \\
\hline & I wear a circle lens to look pretty. & 0.63 & & & \\
\hline \multirow{5}{*}{ Hair care } & I use a hair dryer and an iron on my hair. & 0.57 & \multirow{5}{*}{1.30} & \multirow{5}{*}{$6.22 / 54.41$} & \multirow{5}{*}{0.69} \\
\hline & I regularly have permanents or dye my hair. & 0.76 & & & \\
\hline & I go to the hair salon more than once a month. & 0.69 & & & \\
\hline & I am interested in trendy hairstyles. & 0.55 & & & \\
\hline & I have a hair style that fits my face type. & 0.55 & & & \\
\hline
\end{tabular}


도는 0.63 이고, 외모관리행동 요인5는 헤어 손질, 헤어 관심, 헤어 스타일링으로 구성되어 헤어관리 요인으로 명명하였고, 설명력은 6.22 , 신뢰도는 0.69 로 나타났다.

\section{3. 얼굴 이미지 인식간의 상관관계}

얼굴 중요도와 얼굴 만족도간의 상관관계를 분석한 결과는 Table 5 와 같다. 얼굴 중요도와 얼굴 만족도의 요인 중 대부분의 요 인에서 유의한 상관관계를 나타냈다.

얼굴 중요도 중 얼굴형태는 이목구비 - 헤어, 전체조화 - 피부와 가장 높은 상관관계를 보였고, 얼굴 만족도 중 얼굴형태와 전체조 화 - 피부, 이목구비 · 헤어에 상관관계가 있는 것으로 나타났다. 따라서 얼굴형태를 중요시 하는 사람은 이목구비 · 헤어와 전체조 화 - 피부도 중요하게 생각하고 있으며, 이는 얼굴형태와 피부는 유 의한 연관이 있다는 Baek \& $\operatorname{Kim}$ (2014)의 연구와 같은 맥락이다. 얼굴 중요도 중 이목구비 - 헤어 중요도는 전체조화 - 피부에 가장 높은 상관관계를 나타냈고, 얼굴 만족도 중 이목구비 · 헤어도 높은 상관관계가 있는 것으로 나타났다. 그러나 얼굴 만족도 중 얼굴형 태와 전체조화 - 피부에는 상관관계가 없는 것으로 나타났다. 이는 이목구비 - 헤어를 중요시하는 사람은 얼굴형태와 전체조화 - 피부 도 중요시하며, 이목구비 - 헤어에 만족하지만 얼굴형태와 전체조 화 - 피부에는 불만족함을 의미한다. 얼굴 중요도 중 전체조화 - 피 부 중요도는 얼굴 만족도의 이목구비 · 헤어 만족도와는 상관관계 가 있으나, 얼굴형태와 전체조화 - 피부 만족도와는 상관관계가 없
는 것으로 나타났다. 얼굴 만족도 중 얼굴형태, 이목구비 - 헤어는 전체조화 - 피부 만족도와 매우 높은 상관관계를 보였다. 따라서 얼 굴 중요도의 각 요인들과 얼굴 만족도의 각 요인들은 유의한 상관 관계를 보였으나, 얼굴 중요도와 얼굴 만족도간에는 유의하지 않은 것으로 나타났다.

\section{4. 얼굴 만족여부에 따른 얼굴 이미지 인식}

얼굴 만족여부에 따른 얼굴 이미지 인식을 비교 분석한 결과는 Table 6 과 같다. 여대생의 얼굴 이미지 인식에 관한 얼굴 중요도 평 균은 $4.08 \pm 0.51$, 얼굴 만족도 평균은 $3.23 \pm 0.69$ 로 나타나 얼굴 중요도는 높으나 얼굴 만족도는 상대적으로 낮게 나타났다.

얼굴 중요도를 분석한 결과, 전체조화 - 피부( $4.54 \pm 0.52)$, 이 목구비 · 헤어( $3.90 \pm 0.48)$, 얼굴형태 $(3.80 \pm 0.54)$ 의 순서로 나타 났으며, 얼굴 저만족 집단이 고만족 집단보다 얼굴형태 $(\mathrm{t}=3.30$, $p<0.01)$ 와 전체조화 · 피부 $(\mathrm{t}=2.00, p<0.05)$ 의 중요도를 더 높게 평 가하고 있었다. 특히 얼굴 고만족 집단일수록 얼굴 중요도를 낮게 평가하였다.

얼굴 만족도를 분석한 결과, 이목구비 · 헤어(3.28 \pm 0.60$)$, 전체 조화·피부(3.22 \pm 0.78$)$, 얼굴형태( $3.21 \pm 0.71)$ 의 순서로 나타났 다. 또한 얼굴 저만족 집단과 고만족 집단이 얼굴형태 $(\mathrm{t}=-17.76$, $p<0.001)$, 이목구비 · 헤어 $(\mathrm{t}=-11.41, p<0.001)$, 전체조화 · 피부 $(\mathrm{t}=-11.44, p<0.001)$ 의 모든 요인에서 통계적으로 유의한 차이를 보였다. 특히 얼굴형태 요인에서 가장 큰 집단간 차이를 나타내어

Table 5. Correlation of facial image perception

\begin{tabular}{|c|c|c|c|c|c|c|c|}
\hline \multirow{2}{*}{\multicolumn{2}{|c|}{ Facial image }} & \multicolumn{3}{|c|}{ Facial importance } & \multicolumn{3}{|c|}{ Facial satisfaction } \\
\hline & & 1 & 2 & 3 & 4 & 5 & 6 \\
\hline \multirow{3}{*}{ Facial importance } & 1 Face shape & 1 & $0.39^{* * *}$ & $0.35^{* * *}$ & $-0.14^{* *}$ & $-0.13^{*}$ & $-0.18^{* *}$ \\
\hline & 2 Features.Hair & & 1 & $0.29^{* * *}$ & -0.07 & $-0.17^{* *}$ & -0.10 \\
\hline & 3 Balance-Skin & & & 1 & -0.10 & $-0.11^{*}$ & -0.10 \\
\hline \multirow{3}{*}{ Facial satisfaction } & 4 Face shape & & & & 1 & $0.32^{* * *}$ & $0.40^{* * *}$ \\
\hline & 5 Features.Hair & & & & & 1 & $0.50^{* * *}$ \\
\hline & 6 Balance-Skin & & & & & & 1 \\
\hline
\end{tabular}

${ }^{*} p<0.05 ;{ }^{* *} p<0.01 ;{ }^{* * *} p<0.001$.

Table 6. Facial image perception based on satisfaction with one's face

\begin{tabular}{|c|c|c|c|c|c|}
\hline \multicolumn{2}{|c|}{ Facial image } & $\begin{array}{c}\text { Total } \\
(n=322)\end{array}$ & $\begin{array}{l}\text { Facial satisfaction (low) } \\
(n=163)\end{array}$ & $\begin{array}{l}\text { Facial satisfaction (high) } \\
(\mathrm{n}=159)\end{array}$ & t-value \\
\hline \multirow{3}{*}{$\begin{array}{l}\text { Facial } \\
\text { importance }\end{array}$} & Face shape & $3.80 \pm 0.54^{1)}$ & $3.89 \pm 0.52$ & $3.69 \pm 0.55$ & $3.30^{* *}$ \\
\hline & Features-Hair & $3.90 \pm 0.48$ & $3.88 \pm 0.51$ & $3.80 \pm 0.51$ & 1.30 \\
\hline & Balance-Skin & $4.54 \pm 0.52$ & $4.60 \pm 0.44$ & $4.49 \pm 0.59$ & $2.00^{*}$ \\
\hline \multirow{3}{*}{$\begin{array}{l}\text { Facial } \\
\text { satisfaction }\end{array}$} & Face shape & $3.21 \pm 0.71$ & $2.71 \pm 0.52$ & $3.71 \pm 0.48$ & $-17.76^{* * *}$ \\
\hline & Features-Hair & $3.28 \pm 0.60$ & $2.96 \pm 0.51$ & $3.61 \pm 0.48$ & $-11.41^{* * *}$ \\
\hline & Balance-Skin & $3.22 \pm 0.78$ & $2.80 \pm 0.66$ & $3.65 \pm 0.65$ & $-11.44^{* * *}$ \\
\hline
\end{tabular}

${ }^{*} p<0.05 ;{ }^{* *} p<0.01 ;{ }^{* * *} p<0.001 ;{ }^{1)} \mathrm{M} \pm$ S.D., mean \pm standard deviation. 
얼굴형태 불만족이 얼굴 저만족의 원인으로 연결되는 것으로 보인 다. 이는 얼굴크기, 얼굴모양과 같은 얼굴형태는 메이크업, 헤어 등 으로 보완하기에는 한계가 있기 때문에, 얼굴형태는 성형수술과 같 은 큰 변화를 시도하지 않는 이상 보완에 어려움이 있기 때문이라 는 Lee \& Park (2000)의 연구와 같은 맥락이다. 또한 피부상태가 좋을수록 외모를 긍정적으로 인식한다는 결과는 여대생 외모만족 에 피부가 큰 영향을 미친다는 Seo (2012)의 연구와 일치한다. 따라 서 얼굴형태, 이목구비 · 헤어, 전체조화 - 피부의 모든 요인은 얼굴 만족에 중요한 요인임을 보여준다.

이에 따라 얼굴 만족여부에 따른 얼굴 이미지 인식의 결과를 요 약하면 다음과 같다. 얼굴 중요도는 전체조화 - 피부, 이목구비 - 헤 어, 얼굴형태의 순으로 중요하다고 생각하였고, 얼굴 만족도는 이 목구비 · 헤어, 전체조화 - 피부, 얼굴형태의 순서로 만족하는 것으 로 나타났다. 얼굴 만족여부에 따라 저만족, 고만족 집단으로 분류 한 결과, 얼굴 저만족 집단이 얼굴 고만족 집단보다 얼굴에 대한 중 요도를 더 높이 평가하고 있으며, 얼굴 만족도에서 저만족 집단과 고만족 집단이 모든 요인에서 통계적으로 유의한 차이가 있었다.

\section{5. 얼굴 만족여부에 따른 외모관리행동}

본 연구의 얼굴 만족여부에 따른 외모관리행동을 비교 분석한 결과는 Table 7과 같다. 여대생의 외모관리행동은 피부관리(3.50 $\pm 0.85)$ 가 가장 높았으며 체중조절(3.38 \pm 1.10$)$, 헤어관리( $2.90 \pm$ $0.78)$, 메이크업( $2.82 \pm 0.95)$, 성형 $(2.42 \pm 0.89)$ 의 순서로 나타났 다. 이 중 얼굴 저만족 집단이 성형, 메이크업, 헤어관리 행동이 더 높게 나타났으며 통계적으로 유의한 차이가 있는 것으로 나타났다. 이는 자신의 얼굴이 이상적인 얼굴이 아니라고 생각할 경우 헤어스 타일, 성형, 메이크업을 통해 자신의 얼굴을 보완하려는 것으로 사 료되며, 외모만족도가 낮은 사람일수록 외모관리행동에 더욱 신경 쓰는 경향이 있다는 Park et al. (2009)의 연구와 같은 맥락이다.

이 중 성형은 저만족 집단과 고만족 집단간 가장 큰 차이를 보 였다 $(\mathrm{t}=4.22, p<0.001)$. 외모관리행동 중 성형 행동 자체는 낮은편 (2.42 \pm 0.89$)$ 이었는데, 이는 여대생의 특성상 수입이 적고 학생이 기 때문에 성형을 적극적으로 많이 하지 않기 때문으로 보인다. 그 러나 성형은 메이크업, 체중조절로는 해결하지 못하는 얼굴에 대 한 불만을 가장 단시간에 해결할 수 있는 외모관리행동이며(Hong,
2014), 가장 직접적인 변화를 볼 수 있는 행동이기 때문에 성형수 술이 여대생들에게 적극적인 외모개선 방법 중 하나라는 Lee \& Gang (2009)의 연구와 맥을 같이한다.

메이크업의 경우 얼굴에 저만족 할수록 메이크업을 더 많이 하 는 것으로 나타났다 $(\mathrm{t}=1.96, p<0.05)$. 이러한 결과는 얼굴 만족도가 높을수록 메이크업을 많이 하며(Theberge \& Kernaleguen, 1979), 메이크업 하는 것을 좋아하는 집단이 얼굴 만족도도 더 높다는 Bae $\&$ Ryoo (2004)의 연구와는 차이를 보였다. 이러한 차이는 여대생 의 특성상 대인관계를 위해 메이크업을 활발히 하고, 사회진출을 앞둔 시기 이기 때문에, 이상적인 외모를 추구하기 위해 메이크업 을 시도하며 얼굴의 불만족을 보완하고 얼굴에 더 많은 신경을 쓴 다는 Lee \& Park (2000)와 맥을 같이한다.

헤어 관리에서는 얼굴에 저만족 할수록 헤어 관리를 더 많이 하 는 것으로 나타났다 $(\mathrm{t}=2.56, p<0.05)$. 이는 헤어 스타일링을 통해 불만족스러운 얼굴형의 보완이 가능하며, 자신의 피부톤에 어울리 는 헤어 컬러로 변화를 주는 헤어 관리가 얼굴 저만족 해결에 영향 을 미친다는 Kim \& Nam (2010)의 연구와 맥을 같이한다.

그러나 피부관리, 체중조절은 얼굴 고만족 집단이 저만족 집단 보다 높았으나 통계적으로 유의하지는 않았다. 특히 본 연구의 외

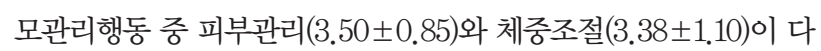
른 외모관리행동보다 더 높게 나타났는데 이는 여대생들에게 피부 관리는 필수이며(Kim \& Nam, 2010), 체중조절은 20대 여성들과 여대생들이 가장 많이 하는 행동(Cho \& Choi, 2007; Kim, 2003) 이라는 선행연구의 결과와 일치한다.

이에 따라 얼굴 만족여부에 따른 외모관리행동의 결과를 요약하 면 다음과 같다. 얼굴 저만족 집단은 자신의 얼굴 저만족 개선을 위 해 성형, 메이크업, 헤어관리 등의 외모관리행동으로 이어지고 있 었으며, 얼굴 고만족 집단의 외모관리행동은 성형, 메이크업, 헤어 관리에서 저만족 집단보다 낮게 나타났다. 이러한 결과는 얼굴 만 족도가 높으면 외모를 개선하려는 인식은 낮아진다는 Hong (2014) 의 연구와 일치한다. 그러나 피부관리, 체중조절에서는 통계적으 로 유의한 차이를 보이지 않았다.

Table 7. Appearance management behavior based on facial satisfaction

\begin{tabular}{|c|c|c|c|c|c|}
\hline \multicolumn{2}{|c|}{ Variable } & $\begin{array}{c}\text { Total } \\
(n=322)\end{array}$ & $\begin{array}{l}\text { Facial satisfaction (low) } \\
\qquad(\mathrm{n}=163)\end{array}$ & $\begin{array}{l}\text { Facial satisfaction (high) } \\
\qquad(\mathrm{n}=159)\end{array}$ & t-value \\
\hline \multirow{5}{*}{$\begin{array}{l}\text { Appearance } \\
\text { management } \\
\text { behavior }\end{array}$} & Plastic surgery & $2.42 \pm 0.89^{1)}$ & $2.62 \pm 0.94$ & $2.21 \pm 0.79$ & $4.22^{* * *}$ \\
\hline & Skin care & $3.50 \pm 0.85$ & $3.45 \pm 0.85$ & $3.54 \pm 0.86$ & -0.97 \\
\hline & Weight control & $3.38 \pm 1.10$ & $3.38 \pm 1.09$ & $3.39 \pm 1.11$ & -0.12 \\
\hline & Makeup & $2.82 \pm 0.95$ & $2.92 \pm 0.93$ & $2.70 \pm 0.97$ & $1.96^{*}$ \\
\hline & Hair care & $2.90 \pm 0.78$ & $3.00 \pm 0.79$ & $2.78 \pm 0.76$ & $2.56^{*}$ \\
\hline
\end{tabular}

${ }^{*} p<0.05 ;{ }^{* *} p<0.01 ;{ }^{* * *} p<0.001 ;{ }^{1)} \mathrm{M} \pm$ S.D., mean \pm standard deviation. 


\section{Conclusion}

본 연구는 서울 - 경기 지역의 여대생 322 명을 대상으로 얼굴 만 족여부에 따른 얼굴 이미지 인식과 외모관리행동에 대하여 알아보 았다. 그 결과는 다음과 같다.

첫째, 얼굴 이미지 요인은 얼굴 만족도와 얼굴 중요도에서 얼굴 형태, 이목구비 - 헤어, 전체조화 - 피부의 각 3 가지 요인으로 나타 났다. 둘째, 외모관리행동의 요인은 성형, 피부관리, 체중조절, 메 이크업, 헤어관리의 5 가지 요인으로 나타났다. 셋째, 얼굴 이미지 의 상관관계는 얼굴 중요도와 얼굴 만족도의 대부분의 요인에서 유 의한 상관관계를 나타냈으나, 얼굴 중요도와 얼굴 만족도에서는 유 의하지 않는 것으로 나타났다. 넷째, 여대생들의 얼굴 이미지 인식 중 얼굴 중요도를 분석한 결과 전체조화 - 피부, 이목구비 · 헤어, 얼굴형태의 순서로 중요도를 인식하는 것으로 나타났으며, 얼굴 저 만족 집단이 고만족 집단보다 얼굴 중요도를 더 높게 평가하고 있 었다. 얼굴 만족도에서는 이목구비 - 헤어, 전체조화 - 피부, 얼굴 형태의 순서로 만족하는 것으로 나타났다. 또한 얼굴 만족도와 얼 굴 중요도를 비교하였을 때 얼굴 중요도는 높게 생각하나 얼굴 만 족도는 상대적으로 낮게 나타났다. 따라서 이상적인 외모에 대한 올바른 인식을 심어주는 것이 필요하다. 여대생의 외모관리행동은 피부관리, 체중조절, 헤어관리, 메이크업, 성형의 순서로 나타났으 며 이 중 얼굴 저만족 집단이 성형, 메이크업, 헤어관리 행동을 더 많이 하고 있으며 통계적으로 유의한 차이를 보였다. 그러나 피부 관리, 체중조절은 얼굴 만족여부에 관계없이 높게 나타났으며 통계 적으로 유의한 차이가 나지 않는 것으로 나타났다.

이러한 결과를 바탕으로 여대생들의 얼굴 만족여부에 따른 얼굴 이미지 인식과 외모관리행동에 관한 기초자료를 제공하고자 하며, 앞으로 뷰티 산업의 잠재 고객인 여대생들에게 얼굴을 비롯한 외모 에 대한 올바른 인식을 가지도록 교육할 필요가 있다.

그러나 본 연구의 제한점은 다음과 같다. 본 연구는 서울 - 경기 지역의 여대생만을 대상으로 하였기 때문에 전국의 여대생으로 일 반화하기에는 한계가 있다. 따라서 후속 연구에서는 전국을 표본으 로 하는 연구가 필요할 것으로 생각된다.

\section{References}

Bae JS, Ryoo HH. A study on expression and the extent of using make-up according to the make-up lifestyle of woman. Journal of the Korean Society of Clothing and Textiles, 28: 332-343, 2004.

Baek KJ, Kim Yl. Formative elements of the facial image of Korean women and the effects of makeup design. Journal of the Korean Society of Costume, 64: 1-20, 2014.
Cho HR, Choi J. Relationship between body satisfaction and appearance enhancement behavior of college students. Korean Journal of Human Ecology, 16: 825-835, 2007.

Choi SK. A study on relation among face cathexis and psychological factors of makeup. Journal of the Korean Society of Design Culture, 15: 365-374, 2009.

Cunningham MR. Measuring the physical in physical attractiveness: quasi-experiments on the sociobiology of female facial beauty. Journal of Personality and Social Psychology, 50: 925-935, 1986.

Daibo I. Social psychology of make-up behavior: sociality of beauty. Fashion \& Textile Research Journal, 4: 223-228, 2002.

Guthrie M, Kim HS, Jung J. The effects of facial image and cosmetic usage on perceptions of brand personality. Journal of Fashion Marketing and Management: an International Journal, 12: 164-181, 2008.

Hassin R, Trope Y. Facing faces: studies on the cognitive aspects of physiognomy. Journal of Personality and Social Psychology, 78: 837-852, 2000.

Hong SN, Kim HS. Effects of extrinsic body satisfaction on beauty management behavior of women of age 20-40. Asian Journal of Beauty and Cosmetology, 10: 829-836, 2012.

Hong SN. The influence of the type of single females' life style in their 20s through 30s on the recognition of the behavior for beauty. Journal of the Korea Fashion \& Costume Design Association, 16: 77-89, 2014.

Kaiser SB. The social psychology of clothing: symbolic appearances in context (2nd edition). Fairchild Pubns, New York, pp134-424, 1996.

Kim JY, Yim EH, Chun HK. Effects of female college students' self-image and media involvement on appearance management behavior. Journal of Fashion Business, 17: 164-178, 2013.

Kim SH. A study on the sociocultural attitude toward appearance and appearance-management behavior: focused on females in their twenties. Family and Environment Research, 41: 99-108, 2003.

Kim YR, Nam MW. The effect of female universities student's beauty care on the stress. Asian Journal of Beauty and Cosmetology, 8: 263-273, 2010.

Kwon WY, Park OL. A study on face satisfaction, appearance care motives and permanent make-up behaviors of 
female consumers by age. Asian Journal of Beauty and Cosmetology, 11: 321-330, 2013.

Lee HO, Park KA. Appearance satisfaction of female consumers: toward the relationships with appearance types and perceptions. Family and Environment Research, 38: 93-102, 2000.

Lee MJ, Chung SJ, Ahn MS. Effect of sociocultural attitudes toward appearance on appearance concerns, appearance management behavior, appearance complex, face satisfaction, and body satisfaction. Journal of the Korean Society of Clothing and Textiles, 39: 323336, 2015.

Lee MY, Gang GH. A study on beauty care behaviors according to female undergraduates' aesthetic consciousness: centering on behaviors in skin care, weight control and cosmetic surgery. Journal of the Korean Society of Esthetics \& Cosmeceutics, 4: 111-126, 2009.

Oh IY, Kim IS. The study on the TV female anchor's image according to the make up and hair style. Journal of the Korean Society of Clothing and Textiles, 30: 1636-1647, 2006.

Park EA, Kim HJ, Suh HS. The relationship among selfconstruals, body value, and appearance management behavior: a cross-cultural study. The Korean Journal of Consumer and Advertising Psychology, 10: 251-274, 2009.
Park SH, Lee HJ. The effects of physical appearance of business women on their career: focused on the women workers at commercial banks in Korea. Korean Journal of Human Ecology, 18: 757-768, 2009.

Ryan MS. Clothing: a study in human behavior. Holt, Rinehart and Winston Publisher, New York, pp260-261, 1966.

Seo RS. The factors that affect the appearance satisfaction result from appearance management behaviors and appearance importance of college woman. Jounal of the Korean Society of Cosmetology, 18: 180-186, 2012.

Song MY, Park OR, Lee YJ. A study on the face image to shape differences and make up. Korean Journal of Human Ecology, 14: 143-153, 2005.

Theberge L, Kernaleguen A. Importance of cosmetics related to aspects of the self. Perceptual and Motor Skills, 48: 827-830, 1979.

Workman JE, Johnson KK. The role of cosmetics in impression formation. Clothing \& Textiles Research Journal, 10: 63-67, 1991.

Yoo TS. Development of facial and make-up images scales. Journal of Korea Design Forum, 32: 281-294, 2011.

Yoon SY, Yoo TS. The effect of hair style for impression formation. Journal of Fashion Business, 5: 73-84, 2001. 


\section{국문초록}

\section{여대생의 얼굴 만족여부에 따른 얼굴 이미지 인식과 외모관리행동에 관한 연구}

최승은

안산대학교 뷰티아트과, 경기도 안산시, 한국

목적: 본 연구는 여대생들의 얼굴 만족여부에 따른 얼굴 이미지 인식과 외모관리행동을 파악하고자 하였다. 방법: 총 322 부가 최종 분석에 사용되었으며, SPSS ver. 23.0 프로그램을 이용하여 빈도 분석, 요인 분석, 신뢰도 분석, 상관 분석 및 t-test 등을 실시하였다. 결과: 얼굴 이미지 인식을 분석한 결과, 전체조화 - 피부, 이목구비 - 헤어, 얼굴형태의 순서로 중요도를 인식하며, 이목구비 · 헤어, 전체조화 - 피부, 얼굴형태의 순서로 만족하는 것으로 나타났다. 또한 얼굴 중요도는 높으나 얼굴 만족도는 상대적으로 낮게 나타났 다. 이후 얼굴 만족여부를 저만족 집단과 고만족 집단으로 나누어 살펴본 결과, 얼굴 저만족 집단이 얼굴 고만족 집단보다 얼굴 중요도 를 좀 더 높게 평가하고 있었고, 얼굴 만족도에서 통계적으로 유의한 차이를 보였다. 외모관리행동에서 얼굴 저만족 집단은 자신의 얼 굴에 대한 저만족을 성형, 메이크업, 헤어관리 등을 통하여 보완하려는 것으로 나타났다. 그러나 피부관리, 체중조절에서는 통계적으 로 유의한 차이를 보이지 않았다. 결론: 본 연구는 여대생들의 얼굴 만족여부에 따라 얼굴 이미지 인식과 외모관리행동에 차이가 있음 을 확인하였다. 본 연구결과를 바탕으로 향후 뷰티 산업의 잠재 고객인 여대생들에게 얼굴을 비롯한 외모에 대한 올바른 인식을 가지 도록 교육할 필요가 있다고 사료된다.

핵심어: 얼굴 이미지, 얼굴 만족도, 얼굴 중요도, 외모관리행동, 여대생

\section{참고문헌}

권우영, 박옥련. 연령별 여성소비자의 얼굴만족도, 외모관리 동기와 퍼머넌트메이크업 행동에 관한연구. 아시안뷰티화장품학 술지, 11: 321-330, 2013.

김영란, 남미우. 여대생의 미용관심 요인이 스트레스에 미치는 영향. 아시안뷰티화장품학술지, 8: 263-273, 2010.

김지양, 임은혁, 전호경. 여대생의 자기이미지와 미디어관여가 외모관리행동에 미치는 영향. 패션 비즈니스, 17: 164-178, 2013.

다이보 이쿠오. 화장행동의 사회심리학: 아름다움의 사회성. 한국의류산업학회지, 4: 223-228, 2002.

박수향, 이혜주. 여성의 외모가 직장생활에 미치는 영향: 은행근무 대상자를 중심으로. 한국생활과학회지, 18: 757-768, 2009.

박은아, 김현정, 서현숙. 문화적 자기개념(self-construals)에 따른 외모중시 가치관과 외모관리행동. 한국심리학회지: 소비

자·광고, 10: 251-274, 2009.

배정숙, 류현혜. 성인 여성의 메이크업 라이프스타일에 따른 메이크업 표현과 사용정도에 관한 연구. 한국의류학회지, $28:$

332-343, 2004.

백경진, 김영인. 한국여성의 얼굴이미지 유형별 형성요소와 메이크업 디자인의 효과. 복식, 64: 1-20, 2014.

서란숙. 여대생의 외모관리행동과 외모의 중요성이 외모만족도에 영향을 미치는 요인. 한국미용학회지, 18: 180-186,

2012.

송미영, 박옥련, 이영주. 얼굴의 형태적 특성과 메이크업에 의한 얼굴 이미지 연구. 한국생활과학회지, 14: 143-153, 2005.

오인영, 김인숙. 메이크업과 헤어스타일 유형에 따른 TV 뉴스 여자 앵커의 인상형성에 관한 연구. 한국의류학회지, 30 :

1636-1647, 2006.

유태순. 화장 전과 후의 얼굴이미지 측정도구개발. 한국디자인포럼, 32: 281-294, 2011.

윤소영, 유태순. Hair Style이 인상형성(印象形成)에 미치는 영향(影響). 패션 비즈니스, 5: 73-84, 2001. 
이민영, 강경호. 여대생의 미의식에 따른 미용관리 행동에 관한 연구: 피부관리, 체중조절, 미용성형 행동 중심으로. 한국피 부미용향장학회지, 4: 111-126, 2009.

이민지, 정성지, 안미선. 외모에 대한 사회문화적 태도가 외모관심도, 외모관리행동, 외모콤플렉스, 얼굴만족도, 신체만족도 에 미치는 영향에 관한 연구. 한국의류학회지, 39: 323-336, 2015.

조혜란, 최종명. 대학생의 성에 따른 신체만족도와 외모향상행동과의 관계. 한국생활과학회지, 16: 825-835, 2007. 최수경. 얼굴만족도와 화장의 심리적 변인과의 관계 연구. 한국디자인문화학회지, 15: 365-374, 2009.

홍수남, 김효숙. 20 - 40대 여성의 외모만족도가 미용관리태도에 미치는 영향. 아시안뷰티화장품학술지, 10: 829-836, 2012. 홍수남. 20 - 30대 미혼여성의 라이프스타일 유형이 뷰티행동인식에 미치는 영향. 한국의상디자인학회지, 16: 77-89, 2014. 


\section{中文摘要}

\section{根据女大学生面部满意度研究面部图像感知和外观管理行为}

\section{崔升銀}

安山大學美容艺术科，京畿道安山市，韩国

目的: 本研究的目的是根据女大学生的面部满意度来识别面部图像感知和外观管理行为。方法: 最终对322份问答卷采用 SPSS 23.0软件进行频率分析、因子分析、可靠性分析、相关分析和t检验。结果: 面部图像感知研究结果, 发现面部图像 的重要性按照整体平衡·皮肤，五官·发型，脸型的顺序依次排列，并且面部满意度按照五官·发型，整体平衡·皮肤，脸型的 顺序依次排列。还发现面部重要性比较高, 而面部满意度相对较低。按照面部满意度划分为低满意度组和高满意度组, 低满意度组比高满意度组表现出更高的面部重要性, 并且面部满意度具有统计学意义上的差异。在外观管理行为上, 低 满意度组通过整形手术、化妆以及发型弥补面部的不足点。皮肤护理和体重控制方面没有统计学意义上的差异。结论: 本 研究证实, 根据女大学生的面部满意度, 面部图像感知和外观管理行为存在统计学意义上的差异。因此, 有必要教育未 来美容产业的潜在顾客-女大学生对外观有正确的认知。

关键词: 图像感知，面部满意度，面部重要性，外观管理行为，女大学生 